\title{
Evaluation of $99 \mathrm{mTcN}-\mathrm{MPO}$ as a New Myocardial Perfusion Imaging Agent in Normal Dogs and in an Acute Myocardial Infarction Canine Model: Comparison with 99mTc-Sestamibi
}

\author{
Lihong Bu ${ }^{1,2,3}$, Renfei $\mathrm{Li}^{2}$, Zhongnan Jin 2 , Xiaofei Wen², Shuang Liu ${ }^{4}$, Baofeng Yang ${ }^{1}$, \\ Baozhong Shen ${ }^{1,2}$, and Xiaoyuan Chen ${ }^{3,5}$ \\ ${ }^{1}$ Department of Pharmacology, Harbin Medical University, 157 Baojian Street, Nangang District, \\ Harbin, Heilongjiang 150001, People's Republic of China \\ ${ }^{2}$ Department of Medical Imaging, the Fourth Hospital of Harbin Medical University, 31 Yinhang \\ Street, Nangang District, Harbin, Heilongjiang 150001, People's Republic of China \\ ${ }^{3}$ Molecular Imaging Program at Stanford (MIPS), Department of Radiology, Stanford University, \\ Stanford, CA 94305-5484, USA \\ ${ }^{4}$ School of Health Sciences, Purdue University, West Lafayette, IN 47907-2036, USA \\ ${ }^{5}$ Laboratory for Molecular Imaging and Nanomedicine, National Institute of Biomedical Imaging \\ and Bioengineering (NIBIB), National Institutes of Health (NIH), 31 Center Drive, Suite 1C14, \\ Bethesda, MD 20892-2281, USA
}

\begin{abstract}
Purpose- ${ }^{99} \mathrm{~m} \mathrm{TcN}-\mathrm{MPO}\left(\left[{ }^{99 \mathrm{~m}} \mathrm{TcN}(\mathrm{mpo})(\mathrm{PNP} 5)\right]^{+}: \mathrm{mpo}=2\right.$-mercaptopyridine oxide and PNP5 $=N$-ethoxyethyl- $N, N$-bis[2-(bis(3-methoxypropyl)phosphino)ethyl]amine) is a cationic ${ }^{99 \mathrm{~m}} \mathrm{Tc}$-nitrido complex, which has favorable biodistribution and myocardial uptake with rapid liver clearance in Sprague Dawley rats. The objective of this study was to compare the biodistribution and pharmacokinetics of ${ }^{99 \mathrm{~m}} \mathrm{TcN}-\mathrm{MPO}$ and ${ }^{99 \mathrm{~m}} \mathrm{Tc}-$ Sestamibi in normal dogs, and to evaluate the potential of ${ }^{99 \mathrm{~m}} \mathrm{TcN}-\mathrm{MPO}$ as a myocardial perfusion agent in canines with acute myocardial infarction.
\end{abstract}

\begin{abstract}
Methods-Five normal mongrel dogs were injected intravenously with ${ }^{99 \mathrm{~m}} \mathrm{TcN}-\mathrm{MPO}$. Venous blood samples were collected via a femoral vein catheter at $0.5,1,2,3,4,5,10,20,30,40,60$, and 90 min post-injection (p.i.). Anterior-posterior planar images were acquired by $\gamma$-camera at 10 , 20, 30, 60, 90, and 120 min p.i. Regions of interest (ROIs) were drawn around the heart, liver, and lungs. The heart/liver and heart/lung ratios were calculated by dividing the mean counts in heart ROI by the mean counts in the liver and lung ROI, respectively. For comparison, ${ }^{99 \mathrm{~m} T c-s e s t a m i b i}$ was also evaluated in the same five dogs. The interval period between the two examinations was 1 week to eliminate possible interference between these two radiotracers. In addition, single positron emission computed tomography (SPECT) images in the canine infarct model were collected $24 \mathrm{~h}$ after myocardial infarction at 30 and 60 min after the administration of ${ }^{99 \mathrm{~m}} \mathrm{TcN}-\mathrm{MPO}(n=4)$ or ${ }^{99 \mathrm{~m}}$ Tc-Sestamibi $(n=4)$.
\end{abstract}

Results-It was found that ${ }^{99 \mathrm{~m}} \mathrm{TcN}-\mathrm{MPO}$ and ${ }^{99 \mathrm{~m}} \mathrm{Tc}-$ Sestamibi displayed very similar blood clearance characteristics during the first 90 min p.i. Both ${ }^{99} \mathrm{~m} \mathrm{TcN}-\mathrm{MPO}$ and ${ }^{99 \mathrm{~m}} \mathrm{Tc}-S e s t a m i b i$ had

(C) Academy of Molecular Imaging and Society for Molecular Imaging, 2010

Correspondence to: Xiaoyuan Chen; shawn.chen@ nih.gov; Baozhong Shen; shenbzh@vip.sina.com.

Lihong Bu and Renfei Li contributed equally to this work 
a rapid blood clearance with less than $50 \%$ of initial radioactivity remaining at $1 \mathrm{~min}$ and less than $5 \%$ at $30 \mathrm{~min}$ p.i. ${ }^{99 \mathrm{~m}} \mathrm{TcN}-\mathrm{MPO}$ and ${ }^{99 \mathrm{~m}} \mathrm{Tc}-$ Sestamibi both showed good heart/lung contrast. The heart/liver ratio of ${ }^{99 \mathrm{~m}} \mathrm{TcN}-\mathrm{MPO}$ increased with time $(0.53 \pm 0.06$ at $10 \mathrm{~min}, 0.90 \pm 0.062$ at $30 \mathrm{~min}$, and $1.22 \pm 0.06$ at $60 \mathrm{~min}$ p.i.), whereas the heart/liver ratio of $99 \mathrm{~m} \mathrm{Tc}$-Sestamibi remained low at all time points $(0.50 \pm 0.03$ at $10 \mathrm{~min}, 0.64 \pm 0.03$ at $30 \mathrm{~min}$, and $0.60 \pm 0.02$ at $60 \mathrm{~min}$ p.i.). SPECT imaging studies in canines with acute myocardial infarction indicated that good visualization of the left ventricular wall and perfusion defects could be achieved at $30 \mathrm{~min}$ after administration of ${ }^{99 \mathrm{~m}} \mathrm{TcN}-\mathrm{MPO}$ but not after ${ }^{99 \mathrm{~m}} \mathrm{Tc}-$ Sestamibi.

Conclusion-The combination of reasonable heart uptake with rapid hepatobiliary excretion makes ${ }^{99 \mathrm{~m}} \mathrm{TcN}-\mathrm{MPO}$ a promising new radiotracer for myocardial perfusion imaging.

\section{Keywords}

99mTcN-MPO; Myocardial perfusion imaging; Biodistribution; Liver clearance; Myocardial infarction; SPECT

\section{Introduction}

Myocardial perfusion imaging (MPI) is a valuable imaging modality for non-invasive evaluations of patients with known or suspected coronary artery disease [1,2]. Ideally, a perfusion radiotracer should have the following characteristics: myocardial uptake directly proportional to blood flow, high extraction fraction, high target-to-background (T/B) ratio, and good myocardial retention. ${ }^{99} \mathrm{mTc}$-Sestamibi has been widely used for MPI in nuclear cardiology. However, it does not meet the requirements of an ideal perfusion imaging agent, due to its high liver uptake [3] and roll-off at higher blood flow levels (and consequent inability to track increases in myocardial blood flow well). The intense liver uptake makes it difficult to interpret the heart activity in the inferior and left ventricular wall [4]. Despite intensive efforts to reduce this interference, photon scattering from high liver activity remains a challenge for accurate diagnosis of heart disease by SPECT. Therefore, it would be of great benefit to develop a new perfusion radiotracer with improved biodistribution and/ or extraction properties [5,6].

Many ether-containing cationic ${ }^{99 \mathrm{~m}} \mathrm{Tc}$ complexes have been reported to have the improved T/B ratios [7-15]. ${ }^{99 \mathrm{~m} T c N-D B O D C 5 ~([99 m ~ T c N(D B O D C)(P N P 5)] ~}{ }^{+}$PNP5= $N$-ethoxyethyl$N, N$-bis[2-(bis(3-methoxypropyl)phosphino) ethyl]amine and $\mathrm{DBODC}=\mathrm{N}, \mathrm{N}$ -

bis(ethoxyethyl)-dithiocarbamato) is under clinical investigation as a new single positron emission computed tomography (SPECT) radiotracer for MPI [16]. Recently, we reported the evaluation of a cationic ${ }^{99 \mathrm{~m}} \mathrm{Tc}$ radiotracer $\left[{ }^{99 \mathrm{~m}} \mathrm{TcN}(\mathrm{mpo})(\mathrm{PNP} 5)\right]^{+}$(Fig. $1:{ }^{99 \mathrm{~m}} \mathrm{TcN}$ MPO) in Sprague Dawley (SD) rats [17]. It was found that ${ }^{99 \mathrm{~m}} \mathrm{TcN}-\mathrm{MPO}$ has a heart uptake between that of $99 \mathrm{~m} \mathrm{Tc}-$ Sestamibi and ${ }^{99 \mathrm{~m}} \mathrm{TcN}-\mathrm{DBODC} 5$. The heart/liver ratio of ${ }^{99 \mathrm{~m}} \mathrm{TcN}$ MPO (12.75 \pm 3.34$)$ was twice as much as that of ${ }^{99 m} \mathrm{TcN}-\mathrm{DBODC} 5(6.01 \pm 1.45)$, and was $>4$ times better than that of ${ }^{99 \mathrm{~m}} \mathrm{Tc}$-Sestamibi $(2.90 \pm 0.22)$ at $30 \mathrm{~min}$ p. i. Planar imaging studies in SD rats indicated that clear heart images could be obtained as early as $15 \mathrm{~min}$ p.i. when ${ }^{99 \mathrm{~m}} \mathrm{TcN}-\mathrm{MPO}$ was used as the radiotracer. It was also demonstrated that ${ }^{99 \mathrm{~m}} \mathrm{Tc}-$ Sestamibi and ${ }^{99 \mathrm{~m}} \mathrm{TcN}-\mathrm{MPO}$ share the same myocardial localization mechanism with almost identical subcellular distribution characteristics [18].

In this study, we determined the blood clearance kinetics of ${ }^{99} \mathrm{~m}$ TcN-MPO in normal dogs and evaluated ${ }^{99 \mathrm{~m} T c N M P O}$ 's potential as a myocardial perfusion radiotracer in canines with acute myocardial infarction. The main objective of this study was to further confirm its fast liver clearance kinetics and to demonstrate its capability, in conjunction with SPECT, to detect myocardial perfusion defects in canines with acute myocardial infarction. 


\section{Materials and Methods}

Chemicals, such as 1,2-diaminopropane- $N, N, N^{\prime}, N^{\prime}$-tetraacetic acid (PDTA), 2-

mercaptopyridine $N$-oxide (mpo; sodium salt) and succinic dihydrazide (SDH), were purchased from Sigma-Aldrich (St. Louis, MO, USA). PNP5 ( $N$-ethoxyethyl- $N, N$-bis[2(bis(3-methoxypropyl)phosphino)ethyl]amine) was prepared according to literature methods $[10,12] \mathrm{Na}^{99 \mathrm{~m}} \mathrm{TcO}_{4}$ was obtained from a Technelite ${ }^{99} \mathrm{Mo} /{ }^{99 \mathrm{~m}} \mathrm{Tc}$ generator (Beijing Senke Ltd). ${ }^{99 \mathrm{~m}} \mathrm{Tc}$-Sestamibi was obtained from the China Institute of Atomic Energy.

\section{9mTcN-MPO}

${ }^{99} \mathrm{mcO}_{4}{ }^{-}$solution $(500-750 \mathrm{MBq})$ was added into a lyophilized mixture of $5 \mathrm{mg}$ of SDH, 5 $\mathrm{mg}$ of PDTA, and $25 \mu \mathrm{g}$ of $\mathrm{SnCl}_{2} \cdot 2 \mathrm{H}_{2} \mathrm{O}$. The reaction mixture ( $\left.\mathrm{pH}=7.5-8.0\right)$ was kept at room temperature for 15-30 min to form the ${ }^{99 \mathrm{~m}}$ Tc-nitrido intermediate. $0.5 \mathrm{~mL} 50 \%$ ethanol was added to a separate vial containing $2 \mathrm{mg}$ of PNP5 and $2 \mathrm{mg}$ of mpo. The resulting solution was added to the vial containing the ${ }^{99 \mathrm{~m}} \mathrm{Tc}$-nitrido intermediate. The mixture was heated at $100^{\circ} \mathrm{C}$ for $\sim 15 \mathrm{~min}$. After cooling to room temperature, a sample of the resulting solution was analyzed by radio-TLC (radiolabeling yield $>90 \%$ ). Doses for imaging studies were made by dissolving the reaction mixture to a concentration of 200-400 $\mathrm{MBq} / \mathrm{mL}$ with saline, before being injected into animals [17].

\section{Animal Preparation}

All experiments were performed in accordance with the NIH animal experiment guidelines (Principles of Laboratory Animal Care, NIH Publication No. 86-23, revised 1985). The protocols for animal studies have been approved by the Harbin Medical University Animal Care and Use Committee (Harbin, China). A total of 13 adult mongrel dogs $(19.5 \pm 0.9 \mathrm{~kg}$, ranging from 18.7 to $21 \mathrm{~kg}$, fasted overnight) were used in this study. The same five normal dogs were used for planar imaging and eight infarcted dogs were used for the SPECT study (four for ${ }^{99 \mathrm{~m}} \mathrm{TcN}-\mathrm{MPO}$ and four for ${ }^{99 \mathrm{~m}} \mathrm{Tc}-\mathrm{Sestamibi}$ ). All dogs were anesthetized by an intravenous (i.v.) injection of $25 \mathrm{mg} / \mathrm{kg}$ sodium pentobarbital $(25-35 \mathrm{mg} / \mathrm{kg})$, intubated with a cuffed endotracheal tube, and ventilated on a respirator with a positive end-expiratory pressure of $4 \mathrm{~cm} \mathrm{H}_{2} \mathrm{O}$ [19]. Additional sodium pentobarbital was provided via i.v. injection to maintain anesthesia as needed.

\section{Blood Clearance Kinetics in Normal Dogs}

Under sodium pentobarbital anesthesia, each animal was administered $370 \mathrm{MBq}$ of ${ }^{99 \mathrm{~m}} \mathrm{TcN}$ MPO or ${ }^{99 \mathrm{~m}}$ Tc-Sestamibi via a femoral vein. Venous blood samples $(1 \mathrm{~mL})$ were collected via a femoral vein catheter at $0.5,1,2,3,4,5,10,20,30,40,60$, and $90 \mathrm{~min}$ p.i. The collected blood samples were weighed and counted for radioactivity in a gamma counter (FT-646, Beijing Nuclear Instrument Factory, China). The radioactivity counts were corrected for background and decay.

\section{Planar Imaging in Normal Dogs}

After the animal was under anesthesia, it was placed supine on a two-head Siemens $\gamma$ camera (E. cam Duet ${ }^{\circledR}$ ) equipped with a parallel hole, low energy, high resolution collimator, and $20 \%$ window centered on the $140-\mathrm{keV}{ }^{99 \mathrm{~m}} \mathrm{Tc}$ photo peak. After administration of $370 \mathrm{MBq}$ of ${ }^{99 \mathrm{~m}} \mathrm{TcN}-\mathrm{MPO}$ via the contralateral femoral vein, anterior and posterior planar images were collected for $2 \mathrm{~min}$ at the specified time points $(10,20,30,60$, 90 , and $120 \mathrm{~min}$ ) using a $256 \times 1,024$ image matrix. The acquisition count limits were set at $500 \mathrm{~K}$. SPECT images were acquired at 40, 70, 90, and $120 \mathrm{~min}$ p.i. and were stored digitally in a $128 \times 128$ matrix. After the completion of image acquisition, animals were allowed to recover. To quantify the images ( $n=5 /$ group), ROIs were drawn around the heart 
(normal left circumflex artery area), liver (gall-bladder area excluded), lung (left lower lobe area), and the kidneys on each image acquired at each time point. The raw activity in each ROI was expressed as counts per minute (cpm)/pixel (decay corrected to injection time). Different organ time-radioactivity curves were thus obtained. The heart/liver and heart/lung ratios were calculated by dividing the mean counts in heart ROI by the mean counts in liver and lung ROI, respectively, for each individual dog. For comparison purposes, ${ }^{99 \mathrm{~m}} \mathrm{Tc}-$ Sestamibi was evaluated using the same protocol as for ${ }^{99 \mathrm{~m}} \mathrm{TcN}-\mathrm{MPO}$ in the same five adult mongrel dogs. The time interval between the two imaging studies in the same dogs was at least 7 days to allow radiation decay and to eliminate possible interference between these two radiotracers.

\section{SPECT in Canines with Myocardial Infarction}

Eight anesthetized dogs underwent femoral artery cannulation and digital subtraction angiography (DSA). Prophylactic lidocaine was administered intravenously to prevent lethal arrhythmia [20]. An acute anterior myocardial infarction animal model was induced on anesthetized dogs by intra-vessel embolism through the second diagonal branch (D2) of the anterior descending artery (LAD) with spongia gelatinosa $(1.0 \mathrm{~mm} \times 1.0 \mathrm{~mm})[21,22]$.

Interruption of the arterial blood stream was affirmed by DSA. The myocardial damage was proved by observing elevated levels of serum aspartate amino-transferase, lactate dehydrogenase, and creatine paosphokinase. SPECT images were acquired on the myocardial infarct dogs at $24 \mathrm{~h}$ after acute myocardial infarction. After the administration of $370 \mathrm{MBq}$ of ${ }^{99 \mathrm{~m}} \mathrm{TcN}-\mathrm{MPO}(n=4)$ or ${ }^{99 \mathrm{~m}} \mathrm{Tc}-\mathrm{Sestamibi}(n=4)$ via contralateral femoral vein, SPECT images were collected for $15 \mathrm{~min}$ at $30 \mathrm{~min}$ and $60 \mathrm{~min}$ p.i., while the animals were still under anesthesia, using $128 \times 128$ projections over $360^{\circ}$. The raw data were stored digitally in a $128 \times 128$ matrix. Myocardial tomograms of vertical major axis, horizontal major axis, and minor axis were reconstructed using a standard filtered backprojection algorithm with a three-dimensional Butterworth filter. The cutoff frequency was at 0.28 cycles/pixel and the slice thickness was $3.9 \mathrm{~mm}$.

\section{Statistical Analysis}

Quantitative data were expressed as mean $\pm \mathrm{SD}$. Means were compared using one-way analysis of variance and Student's t test. $P$ values $<0.05$ were considered statistically significant.

\section{Results}

\section{Blood Clearance Kinetics}

Figure 2 shows the blood radioactivity clearance curves of ${ }^{99 \mathrm{~m}} \mathrm{TcN}-\mathrm{MPO}$ and ${ }^{99 \mathrm{~m}} \mathrm{Tc}-$ Sestamibi in normal mongrel dogs during the first 90 min following tracer administration. The radioactivity was expressed as a percentage of the initial radioactivity level (defined as the value $30 \mathrm{~s}$ after administration of the tracer). Clearly, ${ }^{99 \mathrm{~m}} \mathrm{TcN}-\mathrm{MPO}$ and ${ }^{99 \mathrm{~m}} \mathrm{Tc}-$ Sestamibi each had a rapid blood clearance, with a circulation half-life of 0.90 and $1.0 \mathrm{~min}$, respectively. Less than $5 \%$ of the initial radioactivity remained in the circulation at $30 \mathrm{~min}$ and $<1 \%$ of initial radioactivity remained at $90 \mathrm{~min}$.

\section{Planar Imaging}

Figure 3 illustrates planar images of the normal dogs, following administration of either ${ }^{99 \mathrm{~m}} \mathrm{TcN}-\mathrm{MPO}$ (A) or ${ }^{99 \mathrm{~m}} \mathrm{Tc}-\mathrm{Sestamibi}(\mathrm{B})$. Good-quality images of heart were obtained between $30 \mathrm{~min}$ and $2 \mathrm{~h}$ after ${ }^{99 \mathrm{~m}} \mathrm{TcN}-\mathrm{MPO}$ administration. By contrast, clear heart images were not achieved until $60 \mathrm{~min}$ after ${ }^{99 \mathrm{~m}} \mathrm{Tc}$-Sestamibi administration. 
Figure 4 shows the organ distribution kinetics derived from planar images of normal dogs following administration of either ${ }^{99 \mathrm{~m}} \mathrm{TcN}-\mathrm{MPO}$ or ${ }^{99 \mathrm{~m}} \mathrm{Tc}-$ Sestamibi. ${ }^{99 \mathrm{~m}} \mathrm{TcN}-\mathrm{MPO}$ had a slightly lower initial myocardial radioactivity accumulation than ${ }^{99 \mathrm{~m}} \mathrm{Tc}-\mathrm{Sestamibi}(67.6 \pm 6.2$ $\mathrm{cpm} /$ pixel vs. $81.2 \pm 7.13 \mathrm{cpm} /$ pixel at $10 \mathrm{~min}$ p.i., $p<0.05$ ). The retention of ${ }^{99 \mathrm{~m}} \mathrm{TcN}-\mathrm{MPO}$ in the myocardium was not as good as with ${ }^{99 \mathrm{~m}} \mathrm{Tc}-$ Sestamibi. The myocardium ${ }^{99 \mathrm{~m}} \mathrm{TcN}-\mathrm{MPO}$ radioactivity decreased to $40.8 \pm 2.9$ and $36.6 \pm 2.3 \mathrm{cpm} /$ pixel at 60 and $120 \mathrm{~min}$ p.i., respectively. On the contrary, ${ }^{99 \mathrm{~m}} \mathrm{Tc}-$ Sestamibi showed prolonged retention $(74.9 \pm 6.0$ and $74.3 \pm 4.1 \mathrm{cpm} /$ pixel at 60 and $120 \mathrm{~min}$ p.i.). However, ${ }^{99 \mathrm{~m}} \mathrm{TcNMPO}$ had significantly lower liver uptake than ${ }^{99 \mathrm{~m}} \mathrm{Tc}$-Sestamibi at all time points examined $(p<0.05)$. The ${ }^{99 \mathrm{~m}} \mathrm{TcN}-\mathrm{MPO}$ radioactivity in the liver decreased rapidly from $127.5 \pm 12.1 \mathrm{cpm} /$ pixel at $10 \mathrm{~min}$, to $50.5 \pm 3.5 \mathrm{cpm} / \mathrm{pixel}$ at $30 \mathrm{~min}$, and $40.8 \pm 2.9 \mathrm{cpm} / \mathrm{pixel}$ at $60 \mathrm{~min}$ p.i. By contrast, ${ }^{99} \mathrm{mTc}-$ Sestamibi had a slow decrease from $162.1 \pm 8.0 \mathrm{cpm} / \mathrm{pixel}$ at $10 \mathrm{~min}$ to $123.2 \pm 1.8 \mathrm{cpm} / \mathrm{pixel}$ at $30 \mathrm{~min}$ and to $117.8 \pm 6.8 \mathrm{cpm} / \mathrm{pixel}$ at $60 \mathrm{~min}$ p.i. These results indicated a rapid liver clearance of $99 \mathrm{~m} \mathrm{TcN}-\mathrm{MPO}$, which led to a favorable heart/liver ratio as early as $30 \mathrm{~min}$ after injection. The heart/liver ratio of ${ }^{99 \mathrm{~m}} \mathrm{TcN}-\mathrm{MPO}$ (Fig. 5a) increased from $0.53 \pm 0.06$ at 10 $\min$ p.i. to $0.90 \pm 0.06$ at $30 \mathrm{~min}$ p.i. $(p<0.01)$ and to $1.37 \pm 0.19$ at $120 \mathrm{~min}$ p.i. $(p<0.01)$. On the other hand, the heart/liver ratio of ${ }^{99} \mathrm{~m} \mathrm{Tc}-$ Sestamibi was rather low at early time points $(0.50 \pm 0.03$ at $10 \mathrm{~min}$ and $0.60 \pm 0.02$ at $60 \mathrm{~min})$ and remained less than 1.0 at $120 \mathrm{~min}$ $(0.90 \pm 0.10)$. The gallbladder activity of ${ }^{99 \mathrm{~m}} \mathrm{TcN}-\mathrm{MPO}$ increased rapidly; but increased slowly for ${ }^{99 \mathrm{~m}} \mathrm{Tc}-\mathrm{Sestamibi}$ over the same period.

Both ${ }^{99 \mathrm{~m}} \mathrm{TcN}-\mathrm{MPO}$ and ${ }^{99 \mathrm{~m}} \mathrm{Tc}-$ Sestamibi had good heart/lung ratios (Fig. $5 \mathrm{~b}$ ) over the $2 \mathrm{~h}$ study period ( ${ }^{99 \mathrm{~m} T c N M P O:} 3.77 \pm 0.33$ at $10 \mathrm{~min}$ p.i. and $3.59 \pm 0.20$ at $120 \mathrm{~min}$ p. i.; ${ }^{99 \mathrm{~m} T c-}$ Sestamibi: $3.25 \pm 0.77$ at $10 \mathrm{~min}$ p.i. and $5.70 \pm 1.33$ at $120 \mathrm{~min}$ p.i.).

\section{SPECT Imaging}

Acute myocardial infarction in anesthetized mongrel dogs was induced by femoral artery cannulation. The interruption of arterial blood stream was confirmed by DSA (Fig. 6a). The myocardial damage was proved by observing the elevated levels of serum aspartate aminotransferase (31.4 \pm 1.6 pre-infarction vs. $57.8 \pm 1.9 \mathrm{U} / 1$ post-infarction, $p<0.05)$, lactate dehydrogenase (135.6 \pm 1.9 pre vs. $717.6 \pm 87.0 \mathrm{U} / 1$ post, $p<0.05)$ and creatine phosphokinase $(56.8 \pm 1.5$ pre vs. $384.2 \pm 24.4 \mathrm{U} / 1$ post, $p<0.05)$. The following electrocardiographical changes were used as evidence for acute myocar-dial infarction: appearance of ST elevation, negative $\mathrm{T}$ waves, and pathological Q-waves (Fig. 6b).

Figure 7 illustrates SPECT images of a dog with acute myocardial infarction at 30 and 60 min p.i. A good visualization of the left ventricular wall and perfusion defect could be achieved as early as $30 \mathrm{~min}$ after administration of ${ }^{99 \mathrm{~m}} \mathrm{TcN}-\mathrm{MPO}$ without a stress agent such as adenosine. There was an excellent separation between the heart and surrounding organs. The perfusion defects remained well-defined for $>120 \mathrm{~min}$ p.i. By contrast, there was substantial interference from the liver radioactivity at 30 and $60 \mathrm{~min}$ p.i. in the dog administered ${ }^{99 \mathrm{~m}} \mathrm{Tc}-$ Sestamibi.

\section{Discussion}

The combination of SPECT MPI with a ${ }^{99 \mathrm{~m}} \mathrm{Tc}$-labeled compound is a mainstream imaging modality for detecting and estimating the severity of ischemic heart disease [23,24]. Since contrast with neighboring tissues or organs is a key measure of SPECT MPI image quality, there has been a great deal of effort in the past decade to optimize the biodistribution properties of ${ }^{99 \mathrm{~m}} \mathrm{Tc}$ radiotracers [25].

The in vivo biodistribution behavior of a ${ }^{99 \mathrm{~m}} \mathrm{Tc}$-compound is mainly determined by its physical and chemical properties, such as lipophilicity, molecular shape, size, and oxidation 
state. As previously reported, lipophilicity remains the most important factor affecting both heart uptake and T/B ratios. Crown ethers are very useful functional groups to improve the liver clearance of cationic ${ }^{99 \mathrm{~m}} \mathrm{Tc}$-nitrido complexes. It is the combination of the appropriate DTCs and bisphosphines that results in high heart uptake and fast liver clearance of cationic ${ }^{99 \mathrm{~m}} \mathrm{Tc}$-nitrido complexes.

The principal finding of this study is that ${ }^{99} \mathrm{~m} \mathrm{TcN}-\mathrm{MPO}$ has the desirable characteristics of reasonable heart uptake and fast washout from non-target organs surrounding the heart region. Low liver uptake and rapid hepatobiliary excretion resulted in favorable heart-toliver ratios $(0.90 \pm 0.06)$ as early as $30 \mathrm{~min}$ p.i. The liver and heart time-activity curves of $99 \mathrm{~m} \mathrm{TcN}-\mathrm{MPO}$ crossed at $26.5 \mathrm{~min}$ p.i. After $26.5 \mathrm{~min}$ p.i., the hepatic activity curve was lower than that of the heart (Fig. 4a), whereas time-radioactivity curves of ${ }^{99 \mathrm{~m}} \mathrm{Tc}$-Sestamibi showed that the hepatic activity curve was always above that of the heart (Fig. 4b).

However, the exact mechanism of the relatively lower liver uptake and faster liver clearance of ${ }^{99 \mathrm{~m}} \mathrm{TcN}-\mathrm{MPO}$ compared to ${ }^{99 \mathrm{~m}} \mathrm{Tc}$-Sestamibi is not clear at this stage. It seems that the liver clearance of ${ }^{99 \mathrm{~m}} \mathrm{TcN}-\mathrm{MPO}$ is at least partially caused by the over-expression of multidrug resistance P-glycoproteins (particularly MDR1 Pgp) and multi-drug resistanceassociated proteins (MRPs) in the liver [26-29]. This explanation is supported by the fact that ${ }^{99 \mathrm{~m} T c N M P O}$ has significantly $(p<0.01)$ higher liver uptake and slower liver clearance kinetics in SD rats pre-treated with excess amount of cyclosporin-A, a well-known widespectrum MDR modulator [30], than in those without cyclosporin-A pre-treatment [18]. Further investigations may be necessary to elucidate whether Pgp and MRPs have different impacts on the uptake and retention of ${ }^{99 \mathrm{~m}} \mathrm{TcNMPO}$ and ${ }^{99 \mathrm{~m}} \mathrm{Tc}$-sestamibi.

Our SPECT MPI results showed that left ventricular wall and perfusion defects were clearly visible as early as 30 min post-injection of ${ }^{99} \mathrm{~m}$ TcN-MPO. The perfusion defects remained well-defined over more than $120 \mathrm{~min}$ p.i. (Fig. 7). These promising results demonstrate that ${ }^{99 \mathrm{~m}} \mathrm{TcNMPO}$ is able to detect perfusion defects and the sizes of infarctions within an optimal imaging window of between 30 and 120 min p.i. The early imaging window suggests that ${ }^{99 \mathrm{~m}} \mathrm{TcN}-\mathrm{MPO}$ may shorten the duration of imaging protocols. It is better suited for acutely infarcted patients than ${ }^{99 \mathrm{~m}} \mathrm{Tc}$-Sestamibi, which has an optimal imaging window of 60-120 min p.i. The fact that the perfusion defect is clearly seen without administration of a stress agent provides further support for the validity of this canine infarction model.

The study had some limitations. There is a prolonged retention of ${ }^{99} \mathrm{~m}$ TcN-MPO in the gallbladder due to its hepatobiliary excretion. Considering the location of gallbladder in humans, i.e., not overlapping the heart in an AP projection, this shortcoming may not be a significant issue.

Moreover, various maneuvers (drinking whole milk or eating other fatty food) can help alleviate the problem by causing partial emptying of the gall bladder before repeating imaging [31]. It is also worth mentioning that ${ }^{99 \mathrm{~m}} \mathrm{TcN}-\mathrm{MPO}$ had a decreased myocardial retention over the $2 \mathrm{~h}$ study period and its myocardial radioactivity accumulation was slightly lower than that of ${ }^{99 \mathrm{~m}} \mathrm{Tc}-$ Sestamibi. Thus, early acquisition may be required to achieve a total myocardial count density and compensate for myocardial washout. Our future work will include the determination of the precise kinetics parameters, as well as first pass extraction and its potential to differentiate between viable and ischemic myocardium under both stress and rest conditions. Despite these limitations, ${ }^{99 \mathrm{~m}} \mathrm{TcN}-\mathrm{MPO}$ offers compensating advantages that make it an excellent alternative to ${ }^{99 \mathrm{~m}} \mathrm{Tc}-\mathrm{Sestamibi}$ for myocardial perfusion imaging. 


\section{Conclusions}

The fast blood clearance kinetics, reasonable heart uptake with acceptable myocardial retention, low lung radioactivity, rapid hepatobiliary excretion, and consequently high heart/ liver and heart/lung contrast make ${ }^{99 \mathrm{~m}} \mathrm{TcN}-\mathrm{MPO}$ a potentially better perfusion imaging radiotracer than ${ }^{99 \mathrm{~m}} \mathrm{Tc}-$ Sestamibi. The short waiting time between radiotracer injection and the first available myocardial image is of particular interest for the diagnosis of emergency patients. These advantages warrant its translation to human trials.

\section{Acknowledgments}

This work was supported, in part, by the following research grants: 2009DFB30040 from the international cooperation projects of the Chinese Ministry of Science and Technology, 20070420165 from the National Science Foundation for Postdoctoral Scientists of China, 2007AA3CS085 from the Science and Technology Tackle Key Problem Plan Foundation of Harbin. The authors wish to thank Drs. Fan Wang and Bing Jia from Peking University for technical support.

\section{References}

1. Beller GA, Zaret BL. Contributions of nuclear cardiology to diagnosis and prognosis of patients with coronary artery disease. Circulation 2000;101:1465-1478. [PubMed: 10736294]

2. Jain D. Technetium-99 m labeled myocardial perfusion imaging agents. Semin Nucl Med 1999;29:221-236. [PubMed: 10433338]

3. Llaurado JG. The quest for the perfect myocardial perfusion indicator...still a long way to go. J Nucl Med 2001;42:282-284. [PubMed: 11216527]

4. Kailasnath P, Sinusas AJ. Comparison of Tl-201 with Tc-99 m-labeled myocardial perfusion agents: technical, physiologic, and clinical issues. J Nucl Cardiol 2001;8:482-498. [PubMed: 11481571]

5. Banerjee S, Pillai MR, Ramamoorthy N. Evolution of Tc-99 $\mathrm{m}$ in diagnostic radiopharmaceuticals. Semin Nucl Med 2001;31:260-277. [PubMed: 11710769]

6. Liu S. Ether and crown ether-containing cationic $99 \mathrm{~m}$ Tc complexes useful as radiopharmaceuticals for heart imaging. Dalton Trans 2007;12:1183-1193. [PubMed: 17353949]

7. Lisic EC, Heeg MJ, Deutsch E. ${ }^{99 \mathrm{~m}} \mathrm{Tc}(\mathrm{L}-\mathrm{L}) 3{ }^{+}$complexes containing ether analogs of DMPE. Nucl Med Biol 1999;26:563-571. [PubMed: 10473196]

8. Tisato F, Maina T, Shao LR, et al. Cationic [ $\left.{ }^{99 \mathrm{~m}} \mathrm{TcIII}(\mathrm{DIARS})_{2}(\mathrm{SR})_{2}\right]^{+}$complexes as potential myocardial perfusion imaging agents (DIARS=o-phenylenebis(dimethylarsine); $\mathrm{SR}=$ thiolate). $\mathrm{J}$ Med Chem 1996;39:1253-1261. [PubMed: 8632432]

9. Boschi A, Bolzati C, Uccelli L, et al. A class of asymmetrical nitrido ${ }^{99 \mathrm{~m}} \mathrm{Tc}$ heterocomplexes as heart imaging agents with improved biological properties. Nucl Med Commun 2002;23:689-693. [PubMed: 12089492]

10. Hatada K, Riou LM, Ruiz M, et al. ${ }^{99}$ Tc-N-DBODC5, a new myocardial perfusion imaging agent

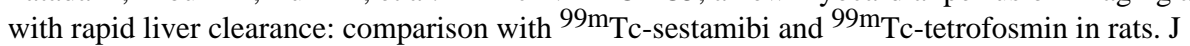
Nucl Med 2004;45:2095-2101. [PubMed: 15585487]

11. Hatada K, Ruiz M, Riou LM, et al. Organ biodistribution and myocardial uptake, washout, and redistribution kinetics of Tc-99 $\mathrm{mN}-\mathrm{DBODC} 5$ when injected during vasodilator stress in canine models of coronary stenoses. J Nucl Cardiol 2006;13:779-790. [PubMed: 17174809]

12. Kim YS, He Z, Hsieh WY, et al. A novel ternary ligand system useful for preparation of cationic ${ }^{99} \mathrm{~m}$ Tc-diazenido complexes and ${ }^{99 \mathrm{~m}} \mathrm{Tc}$-labeling of small biomolecules. Bioconjug Chem 2006;17:473-484. [PubMed: 16536480]

13. Liu S, He Z, Hsieh WY, et al. Evaluation of novel cationic ${ }^{99 \mathrm{~m}} \mathrm{Tc}$-nitrido complexes as radiopharmaceuticals for heart imaging: improving liver clearance with crown ether groups. Nucl Med Biol 2006;33:419-432. [PubMed: 16631092]

14. He Z, Hsieh WY, Kim YS, et al. Evaluation of novel cationic ${ }^{99 \mathrm{~m}} \mathrm{Tc}(\mathrm{I})$-tricarbonyl complexes as potential radiotracers for myocardial perfusion imaging. Nucl Med Biol 2006;33:1045-1053. [PubMed: 17127179] 
15. Kim YS, He Z, Hsieh WY, et al. Impact of bidentate chelators on lipophilicity, stability, and biodistribution characteristics of cationic ${ }^{99} \mathrm{~m}$ Tc-nitrido complexes. Bioconjug Chem 2007;18:929-936. [PubMed: 17352455]

16. Cittanti C, Uccelli L, Pasquali M, et al. Whole-body biodistribution and radiation dosimetry of the new cardiac tracer ${ }^{99 m}$ Tc-N-DBODC. J Nucl Med 2008;49:1299-1304. [PubMed: 18632816]

17. Kim YS, Wang J, Broisat A, et al. Tc-99 m-N-MPO: novel cationic Tc-99 m radiotracer for myocardial perfusion imaging. J Nucl Cardiol 2008;15:535-546. [PubMed: 18674722]

18. Kim YS, Shi J, Zhai S, et al. Mechanism for myocardial localization and rapid liver clearance of Tc-99 m-N-MPO: a new perfusion radiotracer for heart imaging. J Nucl Cardiol 2009;4:571-579. [PubMed: 19288164]

19. Fang W, Liu Y, Zhu L, et al. Evaluation of ${ }^{99} \mathrm{~m}$ TcN-15C5 as a new myocardial perfusion imaging agent in normal dogs and canines with coronary stenosis. Nucl Med Commun 2008;29:775-781. [PubMed: 18677204]

20. Krejcy K, Krumpl G, Todt H, et al. Lidocaine has a narrow antiarrhythmic dose range against ventricular arrhythmias induced by programmed electrical stimulation in conscious postinfarction dogs. Naunyn Schmiedebergs Arch Pharmacol 1992;346:213-218. [PubMed: 1448183]

21. Dib N, Diethrich EB, Campbell A, et al. A percutaneous swine model of myocardial infarction. J Pharmacol Toxicol Methods 2006;53:256-263. [PubMed: 16460969]

22. Katori R, Yamashita K, Miyazaki T, et al. Beta-adrenergic stimulation induces ST-segment elevation in dogs with healing myocardial infarction. Tohoku J Exp Med 1995;177:233-248. [PubMed: 8966719]

23. Chua T, Kiat H, Germano G, et al. Rapid back to back adenosine stress/rest technetium-99 m teboroxime myocardial perfusion SPECT using a triple-detector camera. J Nucl Med 1993;34:1485-1493. [PubMed: 8355068]

24. Berman DS, Germano G, Shaw LJ. The role of nuclear cardiology in clinical decision making. Semin Nucl Med 1999;29:280-297. [PubMed: 10534232]

25. Acampa W, Di Benedetto C, Cuocolo A. An overview of radiotracers in nuclear cardiology. J Nucl Cardiol 2000;7:701-707. [PubMed: 11144485]

26. Lee CH, Bradley G, Zhang JT, et al. Differential expression of P-glycoprotein genes in primary rat hepatocyte culture. J Cell Physiol 1993;157:392-402. [PubMed: 7901227]

27. Mayer R, Kartenbeck J, Buchler M, et al. Expression of the MRP gene-encoded conjugate export pump in liver and its selective absence from the canalicular membrane in transport-deficient mutant hepatocytes. J Cell Biol 1995;131:137-150. [PubMed: 7559771]

28. Agrawal M, Abraham J, Balis FM, et al. Increased 99mTc-sestamibi accumulation in normal liver and drug-resistant tumors after the administration of the glycoprotein inhibitor, XR9576. Clin Cancer Res 2003;9:650-656. [PubMed: 12576431]

29. Gatmaitan ZC, Arias IM. Structure and function of P-glycoprotein in normal liver and small intestine. Adv Pharmacol 1993;24:77-97. [PubMed: 8099292]

30. Qadir M, O'Loughlin KL, Fricke SM, et al. Cyclosporin A is a broad-spectrum multidrug resistance modulator. Clin Cancer Res 2005;11:2320-2326. [PubMed: 15788683]

31. van Dongen AJ, van Rijk PP. Minimizing liver, bowel, and gastric activity in myocardial perfusion SPECT. J Nucl Med 2001;41:1315-1317. [PubMed: 10945520] 

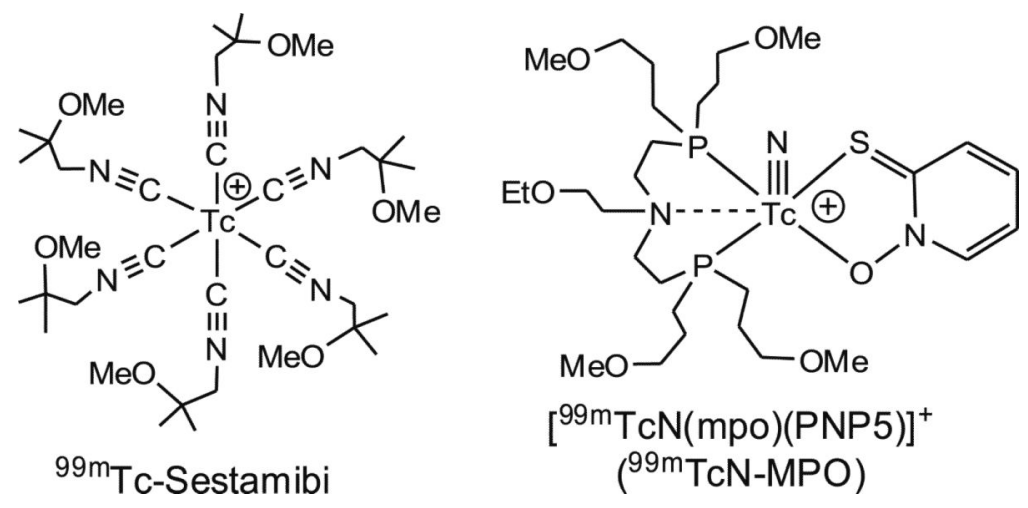

Fig. 1.

Structures of ${ }^{99} \mathrm{~m} \mathrm{TcN}-\mathrm{MPO}$ and ${ }^{99 \mathrm{~m}} \mathrm{Tc}-$ Sestamibi. 


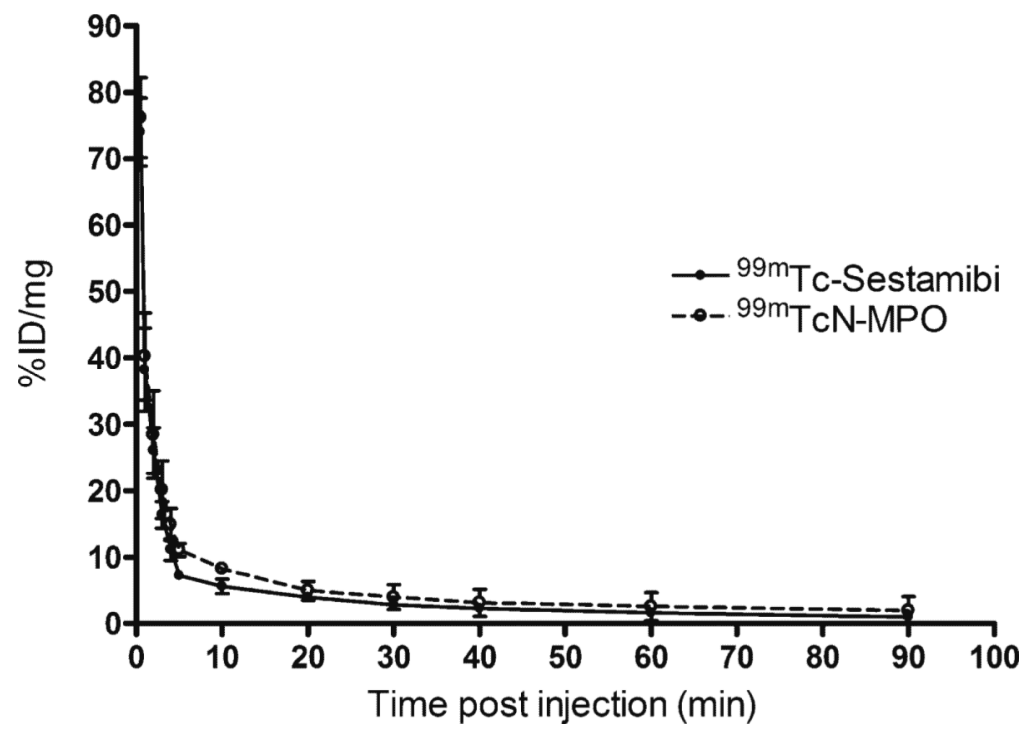

Fig. 2.

Blood clearance curves of ${ }^{99} \mathrm{~m}$ TcN-MPO (blank circle) and ${ }^{99} \mathrm{~m}$ Tc-Sestamibi (filled circle) in normal mongrel dogs. Both tracers showed rapid blood clearance with less than $5 \%$ of initial radioactivity remaining at $30 \mathrm{~min}$ p.i. 


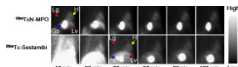

Fig. 3.

Planar images of normal dogs administered ${ }^{99} \mathrm{~m}$ TcN-MPO or ${ }^{99} \mathrm{~m}$ Tc-Sestamibi. Both radiotracers had reasonable myocardial uptake. The liver clearance of ${ }^{99 \mathrm{~m}} \mathrm{TcN}-\mathrm{MPO}$ was faster than that of ${ }^{99 \mathrm{~m}}$ Tc-Sestamibi. $G b$ gallbladder, $H$ heart, $L g$ lung, $L v$ liver. 


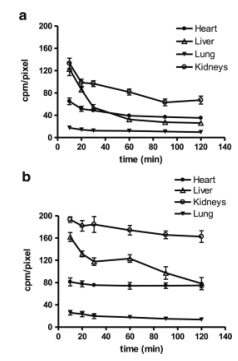

Fig. 4.

Organ clearance kinetics from imaging quantification in normal dogs administered ${ }^{99 \mathrm{~m}} \mathrm{TcN}-$ MPO (a) or ${ }^{99} \mathrm{~m}$ Tc-Sestamibi (b). The liver activity of ${ }^{99} \mathrm{~m}$ TcN-MPO was markedly decreased within the first $60 \mathrm{~min}$, whereas ${ }^{99 \mathrm{~m}}$ Tc-Sestamibi had a slower reduction in liver activity over time. A mild myocardial washout was observed in the dogs administered ${ }^{99 \mathrm{~m}} \mathrm{TcN}-\mathrm{MPO}$. No significant myocardial washout was seen in the dogs administered ${ }^{99 \mathrm{~m}} \mathrm{Tc}-$ Sestamibi. 

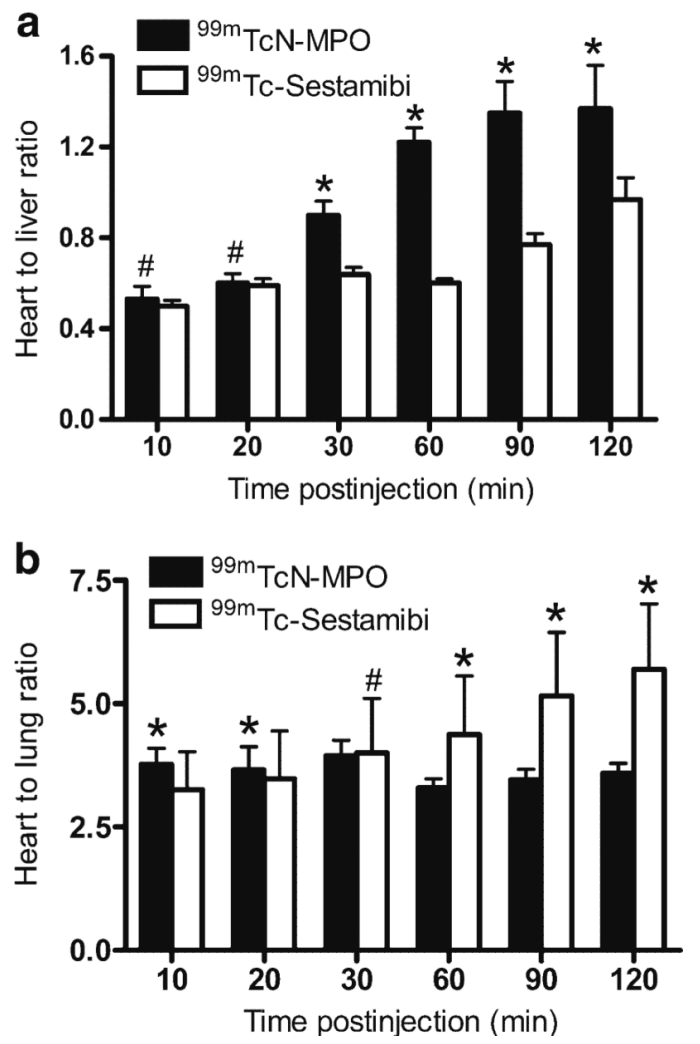

Fig. 5.

Comparison of heart/liver (a) and heart/lung (b) ratios for ${ }^{99}{ }^{9} \mathrm{TcN}-\mathrm{MPO}$ and ${ }^{99 \mathrm{~m}} \mathrm{Tc}-$

Sestamibi in normal dogs. Both tracers had good heart/lung contrast. The heart/liver ratio of ${ }^{99 \mathrm{~m}} \mathrm{TcN}-\mathrm{MPO}$ increased rapidly over the $2 \mathrm{~h}$ study period, whereas the heart/liver ratio of ${ }^{99} \mathrm{~m}$ Tc-Sestambi improved only slightly with time (single number sign P>0.05; asterisk $P<0.05)$. 


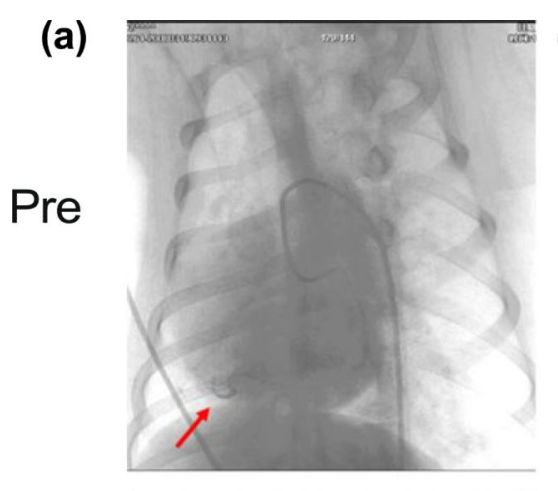

(b)
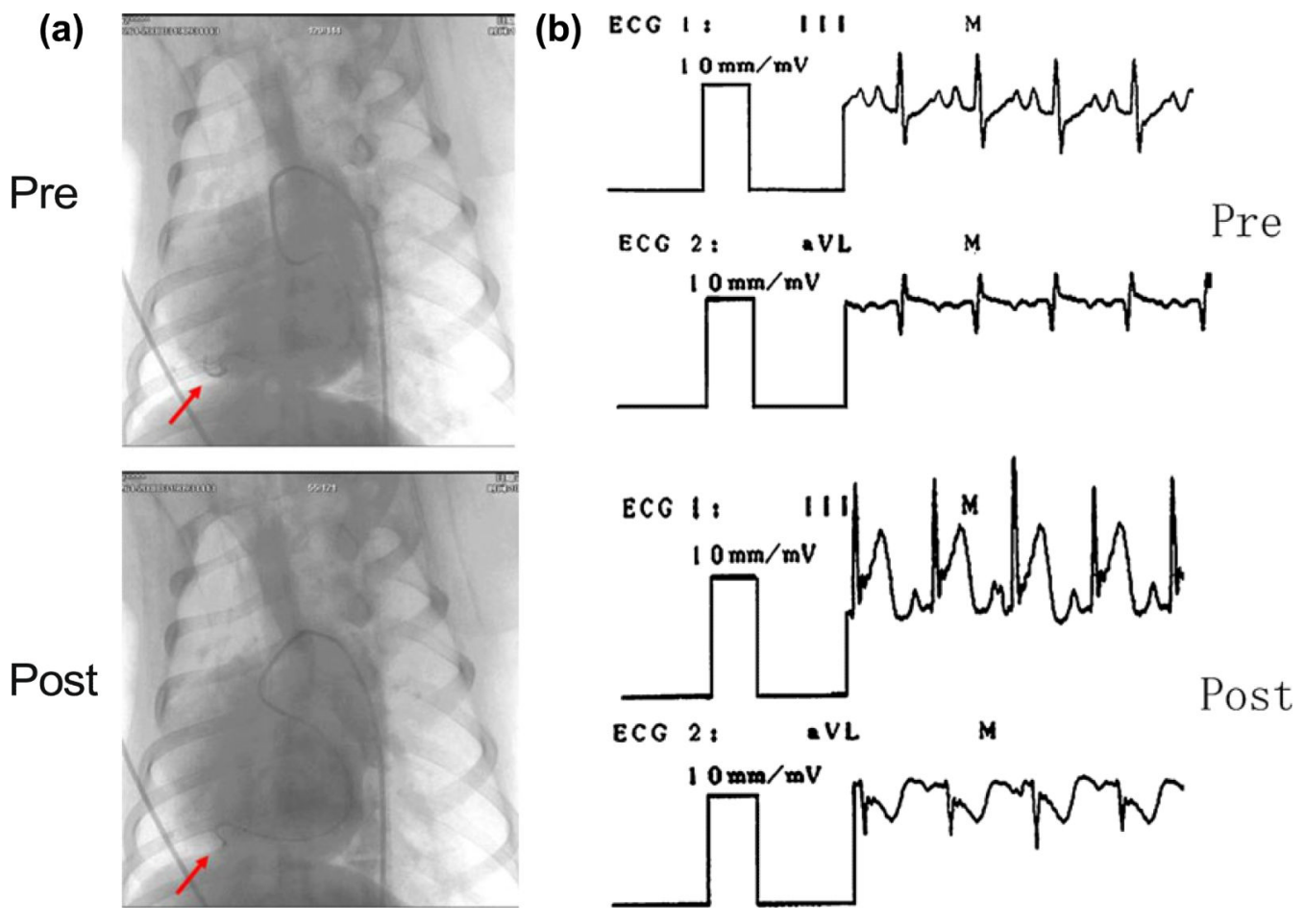

Fig. 6.

Validation of acute myocardial infarction in mongrel dogs. a Digital subtraction angiography (DSA) shows that the D2 of the anterior descending artery (LAD) was interrupted after infarction. Arrow points to D2. b Electrocardiograms indicated ST segment elevation in lead III and ST segment depression in lead aVL after infarction. 


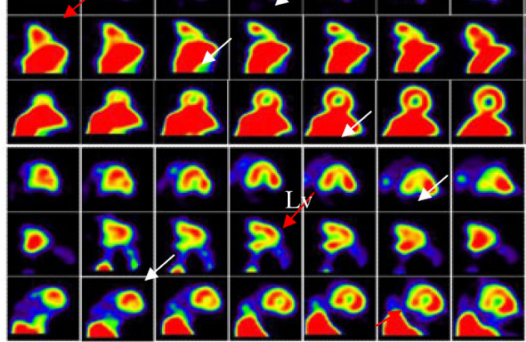

$30 \mathrm{~min}$

99mTcN-MPO
${ }^{99 m}$ Tc-sestamibi
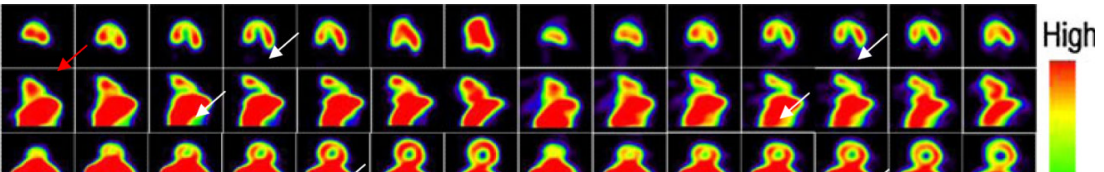

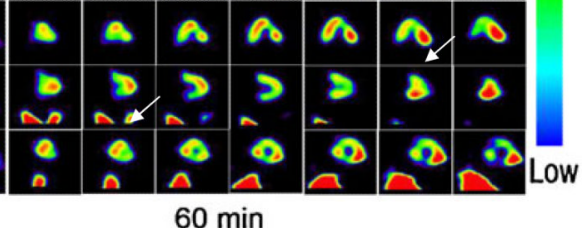

Fig. 7.

SPECT images of dogs with acute myocardial infarction administered ${ }^{99 \mathrm{~m} T c-S e s t a m i b i}$ or ${ }^{99 \mathrm{~m}} \mathrm{TcN}-\mathrm{MPO}$ at 30 and $60 \mathrm{~min}$ p.i. The perfusion defects are indicated by white arrows. Arrows show the liver and gallbladder. Anterior myocardial infarctions near the apex are visible. 